\title{
Avaliação do Comportamento do Motorista, Lócus de Controle e Estilos de Direção no Trânsito
}

\author{
Jocemara Ferreira Mognon ${ }^{1}$ \\ Acácia Aparecida Angeli dos Santos \\ Universidade São Francisco, Campinas, SP, Brasil
}

\section{Resumo}

Este estudo teve como objetivo analisar o comportamento do condutor, o lócus de controle no trânsito e os estilos de condução. Participaram 326 motoristas, com idades entre 19 a 75 anos $(M=38,27 ; D P=$ $11,54)$, sendo 55,5\% do sexo feminino e tempo de habilitação de 1 a 49 anos $(M=15,69 ; D P=10,80)$. Os instrumentos utilizados foram o Questionário de Comportamento do Condutor (QCM), a Escala de Lócus de Controle para o trânsito (T-LOC-BR) e a Escala Multidimensional dos Estilos de direção (MSDI). Os resultados indicaram que os erros, lapsos e violações do condutor se mostraram positivamente correlacionados com a atribuição da ocorrência de acidentes a motivos internos e ao acaso, bem como aos estilos de condução agressivo e negligente. As análises dos escores dos três instrumentos revelaram, ainda, diferenças significativas relativas às variáveis sociodemográficas. Acredita-se que os achados deste trabalho contribuem para a ampliação do conhecimento sobre o comportamento do condutor, contudo há a necessidade da realização de novos estudos.

Palavras-chave: Psicologia do trânsito, comportamentos de risco, infrações.

\section{Driver's Behavior Assessment, Locus of Control and Driving Styles in Traffic}

\begin{abstract}
This study aimed to analyze driver's behavior, the locus of control in traffic and driving styles. Three hundred and twenty six drivers participated in the present study, aged 19-75 years $(M=38.27 ; S D=$ $11.54), 55.5 \%$ being female and with years of driving between 1 and $49(M=15.69 ; S D=10.80)$. The instruments used were the Driver Behavior Questionnaire (QCM), the Traffic Locus of Control (T-LOC-BR) and the Multidimensional Driving Styles Inventory (MSDI). Results indicated that errors, lapses and drivers' violations were positively correlated with causal attributions of accidents to internal reasons and chance, as well as with aggressive and careless driving styles. The analysis of scores obtained from the three instruments also revealed significant differences with regard to sociodemographic variables. We believe these findings contribute to a better understanding of drivers' behavior, however, further studies are needed.
\end{abstract}

Keywords: Traffic psychology, risk behaviors, traffic violations.

1 Endereço para correspondência: Universidade São Francisco, Campus de Campinas, Rua Waldemar César da Silveira, Jardim Cura D'Ars, Campinas, SP, Brasil 13045510. Fone: (11) 37793300. Ramal: 3371. E-mail: jocemognon@gmail.com e acacia.angeli@gmail.com

Financiamento: Coordenação de Aperfeiçoamento de Pessoal de Nível Superior (CAPES). 


\section{Evaluación del Comportamiento del Conductor, Locus de Control y Estilos de Conducción en el Tránsito}

\section{Resumen}

Este estudio tuvo como objetivo analizar el comportamiento del conductor, el locus de control en el tráfico y estilos de conducción. Participaron 326 conductores, edad 19-75 años ( $M=38.27 ; D E=11.54)$, $55,5 \%$ mujeres y el tiempo de habilitación $1-49$ años $(M=15.69 ; D E=10.80)$. Los instrumentos utilizados fueron el Cuestionario de comportamiento del conductor (QCM), la Escala de Locus de control de tránsito (T-LOC-BR) y la Escala Multidimensional de Estilos de dirección (MSDI). Los resultados errores, lapsus y violaciónes del conductorse encuentran correlacionados positivamente, con la asignación de los accidentes a razones internas y por acaso, y también a los estilos de conducción agresiva y descuidados. El análisis de las puntuaciones de los tres instrumentos también reveló diferencias significativas en las variables sociodemográficas. Se cree que los resultados de este estudio han contribuido a la expansión del conocimiento sobre el comportamiento del conductor, pero la necesidad de nuevos estudios.

Palabras clave: Psicología del tráfico, comportamientos de riesgo, delitos.

O comportamento do condutor tem sido considerado o principal motivo para o envolvimento em acidentes de trânsito (Rozestraten, 1988). Especialmente devido a fatores como erros e violações às leis de trânsito, os quais podem contribuir de forma isolada como também combinados (Hoffmann, 2005). Reason, Manstead, Stradling, Baxter e Campbell (1990), buscando compreender os comportamentos dos condutores, desenvolveram o Driver Behaviour Questionnaire (DBQ) composto por três fatores: (a) erros; (b) lapsos e (c) violações na direção.

Por definição, os erros e os lapsos são resultantes de problemas no processamento cognitivo (Özkan, Lajunen, \& Summala, 2006; Steg \& Brussel, 2009). Os erros são usados genericamente para denominar todas as ocasiões em que uma sequência planejada de atividades mentais ou físicas não atinge o resultado pretendido (Reason et al., 1990). Por sua vez, os lapsos referem-se a falhas de atenção e memória (por exemplo, esquecer os faróis ligados ou tentar dar partida em marcha errada), que são relativamente menos perigosos do que os erros (Lajunen \& Summala, 2003). Segundo Rimmö e Hakamies-Blomqvist (2002), existe outro tipo de comportamento que está associado com atitudes e a motivação, denominado de violações. Neste caso, existe uma intencionalidade do com- portamento e o condutor geralmente sabe que está fazendo algo que infringe as leis de trânsito (Veiga, Pasquali, \& Silva, 2009).

A versão original e adaptada do Driver Behaviour Questionnaire (DBQ) tem sido amplamente utilizada para avaliação do comportamento dos motoristas em vários países (Wahlberg, Dorn, \& Kline, 2011) e os resultados obtidos têm mostrado relação com violações e acidentes de trânsito, apesar de pouca consistência das investigações sobre quais os fatores do DBQ de fato apresentam essas associações. Nos achados de DeLucia, Bleckley, Meyer e Bush (2003), por exemplo, as violações avaliadas pelo DBQ foram preditoras dos acidentes, tal como ocorreu na pesquisa de Özkan e Lajunen (2005) que revelou correlação entre as violações e acidentes de trânsito $(r=$ $0,35, p<0,001)$. Por sua vez, Freeman, Wishart, Davey, Rowland e Williams (2009) identificaram em sua pesquisa correlações positivas, de magnitude fraca $(r=0,16, p<0,001)$ entre erros e acidentes, enquanto Stephens e Groeger (2009) encontraram índice de correlação semelhante, mas no sentido negativo, entre lapsos e acidentes $(r=-0,16, p<0,001)$.

$\mathrm{Na}$ meta-análise realizada por Winter e Dodou (2010) com 174 pesquisas, os autores concluíram que os fatores erros e as violações do DBQ correlacionaram-se positivamente com 
envolvimento em acidentes, mas somente as violações foram preditoras de acidentes entre os motoristas jovens. Entretanto, Wahlberg, Dorn, Winter, Dodou e Freeman (2012) analisaram criticamente a meta-análise realizada por Winter e Dodou, levantando vários questionamentos, dentre eles, o de que o Driver Behaviour Questionnaire (DBQ) não tem poder preditivo comprovado para o envolvimento com acidentes de trânsito.

Apesar das críticas levantadas por Wahlberg et al. (2012) ao DBQ, ele é um instrumento bastante utilizado nas pesquisas, já tendo sido adaptado para vários países e servido de base para o desenvolvimento de outros questionários e escalas que avaliam o comportamento de motoristas. Isso ocorre proeminentemente, pelo fato de ele avaliar dois comportamentos muito presentes no ato de dirigir, erros e violações (Cordazzo, Scialfa, Bubric, \& Ross, 2014). Segundo os autores, os motoristas muitas vezes se envolvem em comportamentos que representam um risco para si e para outros motoristas e pedestres. Consideram ainda que, embora muitos desses atos sejam violações de regras, outros são resultados de erros devido a situações momentâneas, que podem ser atribuídos à inexperiência ou desatenção. Além disso, as controvérsias existentes sobre os resultados com o DBQ instigam o desenvolvimento de novas pesquisas e de novos instrumentos que avaliem o comportamento do condutor.

Quando comparadas as variáveis sociodemográficas, diversos estudos têm encontrado diferenças estatisticamente significativas nos resultados do DBQ. Mesken, Lajunen e Summala (2002), por exemplo, reportaram que as incidências de erros aumentam com a idade, além de ocorrerem mais frequentemente entre as mulheres. Na revisão feita por Winter e Dodou (2010), também foi verificado, com o avanço da idade, o aumento no número de erros simultaneamente à diminuição das violações. Entretanto, os resultados indicaram que as violações aumentam com o número de quilômetros rodados. Correia $\mathrm{e}$ Horta (2014) identificaram em sua pesquisa, que os homens motoristas cometeram mais violações e encontraram também correlação entre o traço de personalidade busca de sensações e os fatores lapsos e violações do DBQ.

No Brasil, alguns estudos têm sido desenvolvidos com versões adaptadas do DBQ. Os resultados, relativos ao comportamento do condutor, indicaram que os homens apresentaram maior frequência de erros no trânsito e que não há diferenças significativas para o estado civil (Soares, 2007). Também foram detectadas correlações positivas e estatisticamente significativas entre os traços de raiva e de agressividade, com os fatores erros e violações do DBQ (Monteiro \& Günter, 2006) e, entre a característica de personalidade irritabilidade e o fator violações (Tawamoto \& Capitão, 2010). Além disso, variáveis como escolaridade, frequência de dirigir, consumo de bebida alcoólica e assunção de infrações de trânsito de outras pessoas foram preditores de violações (Pasa, 2013). Por fim, o fator violação apareceu como um preditor de acidentes de trânsito (Olandoski, 2012).

Vale ressaltar que o comportamento do motorista é bastante complexo e envolve mais que habilidades cognitivas, mas também aspectos motivacionais, atitudes e crenças relacionados ao ato de dirigir. Assim, o lócus de controle é mais um dos fatores que ajudam na compreensão dos comportamentos de risco no trânsito, o qual contribui para a adaptação e predição dos comportamentos de condução segura (Huang \& Ford, 2012; Warner, Özkan, \& Lajunen, 2010).

De forma geral, o lócus de controle é definido como a maneira pelas quais os indivíduos atribuem responsabilidades pelos eventos que ocorrem em suas vidas a fatores internos ou externos (Özkan \& Lajunen, 2005). Especificamente para o trânsito, o lócus de controle interno pode influenciar o comportamento em termos de segurança, uma vez que motoristas classificados com esse tipo de lócus tendem a perceber que os resultados são dependentes de suas próprias habilidades, esforços ou comportamento (Huang \& Ford, 2012). Assim, esses motoristas são mais propensos a usar o cinto de segurança regularmente (Hoyt, 1973) e a utilizar medidas de precaução, como por exemplo, aplicar os freios mais rapidamente ao perceber um peri- 
go na pista de condução (Lajunen \& Summala, 1995). No entanto, os motoristas que acreditam que os resultados são controlados por forças externas podem ser mais resistentes para mudar os seus comportamentos (Huang \& Ford, 2012), sendo que esse tipo de lócus aparece associado ao envolvimento em acidentes de trânsito fatais (Montag \& Comrey, 1987), bem como à falta de cuidado e de precauções para evitar a ocorrência de desfechos desfavoráveis (Özkan, Lajunen, Doğruyol, Zümrüt, \& Çoymak, 2011).

Dada a importância desse construto, foram desenvolvidos alguns instrumentos que avaliam o lócus de controle no trânsito. A escala elaborada por Özkan e Lajunen (2005) foi denominada Traffic Locus of Control (T-LOC) e apresenta quatro subescalas que incluem: fatores internos, fatores externos referentes a outros condutores, fatores externos referentes ao ambiente e fatores externos referentes ao acaso (como por exemplo, má sorte, destino). Os autores aplicaram-na em jovens condutores e os resultados mostraram que os motoristas que atribuíram as causas dos acidentes ao próprio comportamento (internalidade) estiveram envolvidos mais frequentemente em acidentes e tiveram maior número de violações de trânsito do que aqueles que atribuíram acidentes a fatores externos (externalidade).

No Brasil, o T-LOC-BR foi adaptado por Olandoski (2012). Os resultados do estudo apontaram para a existência de diferenças estatisticamente significativas com maiores médias para as mulheres nos fatores de externalidade-outros e externalidade-acaso, bem como para os motoristas com mais de 23 anos de idade e também para os que já sofreram acidentes de trânsito no fator externalidade-outros. Foram encontradas correlações indicando que quanto maior o tempo de habilitação maior a atribuição das causas de acidentes a fatores internos. Foram encontradas correlações positivas, porém de magnitude fraca, entre os fatores erros e lapsos do Driver Behaviour Questionnaire (DBQ) com o fator internalidade, respectivamente, $(r=0,16 ; r=0,12)$ do T-LOC-BR. Os resultados revelaram, ainda, correlação positiva entre os lapsos e o fator externalidade-acaso do T-LOC-BR $(r=0,12)$, bem como correlação negativa entre o fator vio- lações do DBQ e o fator externalidade-outros $(r=-0,11)$ do T-LOC-BR.

O lócus de controle pode não só influenciar o comportamento do condutor, como também apresentar relação com os estilos de direção, tal como identificado por Holland, Geraghty e Shah (2010) ao avaliar 222 jovens condutores. Os resultados obtidos indicaram que os motoristas que pontuaram mais em lócus de controle externo obtiveram também maiores pontuações nos estilos de condução senso-emocional, perigoso e estressado. Os autores verificaram ainda diferenças relativas ao sexo, com maiores médias para os homens nos estilos de dirigir perigoso, estressado e negligente e para as mulheres nos estilos de condução relaxante, preventivo e desatento.

Para Taubman-Ben-Ari, Mikulincer e Gillath (2004), o estilo de condução refere-se às formas como os motoristas conduzem habitualmente no trânsito, incluindo a velocidade, a atenção, assertividade no relacionamento com outros motoristas, emoção, sentimentos, crenças, valores e atitudes. Os autores construíram uma medida para avaliar os estilos de direção denominada de Multidimensional Driving Style Inventory (MDSI). Os itens foram construídos com base em instrumentos que avaliam o comportamento do condutor, dentre eles, o Drive Behaviour Questionnaire (DBQ). Participaram do estudo 328 motoristas de Israel e, a análise fatorial exploratória indicou oito estilos de direção: (a) dissociativo; (b) ansioso; (c) arriscado; (d) perigoso; (e) raivoso; (f) paciente; (g) cuidadoso e (h) relaxante.

O primeiro estilo foi nomeado como dissociativo e sugere uma tendência do motorista a ficar facilmente distraído durante a condução, podendo, com isso, cometer erros. Para o ansioso, as pessoas tendem a se sentirem desconfortáveis durante a condução, podendo expressar dúvidas e falta de confiança sobre suas habilidades na direção. Há também o estilo arriscado, referente ao motorista que busca estimulação, novas sensações e comportamentos de risco. Por sua vez, o condutor com o estilo perigoso tende a dirigir muito rápido, diante da pressão de tempo. No raivoso, o motorista apresenta a tendência de ser hostil com outros motoristas, comportando-se de 
forma agressiva durante a condução. Para o motorista paciente, caracteriza-se pela tendência de ser educado com outros motoristas, além de gentil e empático. No estilo cuidadoso, o motorista planeja sua condução de forma eficaz, adotando atitudes de resolução de problemas relacionados com a condução e os obstáculos e, por fim, no relaxante, os motoristas utilizam-se de estratégias, tais como ouvir música e exercícios de respiração com o intuito de reduzir a tensão na direção.

Dois estudos foram realizados com o MSDI, comparando os estilos de direção dos pais e dos filhos e relacionando-os com traços de personalidade (Miller \& Taubman-Ben-Ari, 2010; Taubman-Ben-Ari, Mikulincer, \& Gillath, 2005). Os resultados indicaram correlações positivas entre o estilo negligente com baixa autoestima, violações e histórico de envolvimento em acidentes de trânsito. Também têm se encontrado na literatura que características de personalidade como a busca por sensação e a agressividade apareceram relacionadas de maneira positiva com os estilos raiva e risco e negativamente com o estilo de condução cuidadosa (Poó, Taubman-Ben-Ari, Ledesma, \& Diáz-Lázaro, 2013), sendo essas duas características as principais preditoras do estilo de condução arriscada (Poó \& Ledesma, 2013). No estudo de Trógolo, Melchior e Medrano (2013) foi identificado, por um lado, que as dificuldades na regulação emocional estão associadas aos estilos de condução ansioso, irritado, dissociativo e arriscado. Por outro lado, dificuldades menores em controlar as emoções foram associadas à condução cuidadosa.

No Brasil, a adaptação do MSDI foi realizada por Silva (2004) e após os procedimentos de tradução para o português e de retroversão, os resultados indicaram oito estilos de dirigir, denominados de estressado, agressivo, negligente, perigoso, senso-emocional, preventivo, relaxante e desatento. Vale a ressalva que, apesar de ter sido mantido o mesmo número de fatores, os itens ficaram com uma configuração diferente do instrumento original de Taubman-Ben-Ari et al. (2004) e, por isso, foram nomeados diferentemente. Além disso, os resultados indicaram que o estilo preventivo estava negativamente associado ao estilo desatento e que os homens apresentaram maiores médias no estilo relaxante e as mulheres no estilo desatento. Para a variável idade, foram encontradas correlações significativas e negativas com os estilos perigoso, senso-emocional e desatento, e positiva com o estilo preventivo.

Considerando a literatura apresentada, os construtos focalizados nesta pesquisa têm sido estudados em diversos países a fim de fornecer mais elementos explicativos sobre os comportamentos dos motoristas. No Brasil, mesmo havendo instrumentos adaptados para avaliação desses construtos, as investigações a respeito são escassas. Além do mais, estudar aspectos comportamentais dos motoristas pode ser útil para a elaboração de futuras intervenções no trânsito, contribuindo também para o aumento da escassa produção científica em Psicologia do trânsito no Brasil. Nesta perspectiva, o objetivo deste estudo foi analisar a correlação entre comportamento do motorista (QCM), lócus de controle no trânsito (T-LOC-BR) e estilos de direção (MSDI). Adicionalmente, a relação destes construtos com variáveis como idade, tempo de habilitação, frequência com que dirige, número de infrações e acidentes de trânsito, bem como possíveis diferenças com outras variáveis sociodemográficas como sexo, escolaridade e estado civil.

\section{Método}

\section{Participantes}

Participaram da pesquisa 326 motoristas que residiam em Curitiba-PR, capital e cidades do interior de São Paulo, com idade entre 19 a 75 anos $(M=38,27 ; D P=11,54)$, sendo $55,5 \%(n=$ $181)$ do sexo feminino, $73 \%(n=241)$ com ensino superior. O tempo que possuem a Carteira Nacional de Habilitação $(\mathrm{CNH})$ variou de 1 a 49 anos $(M=15,69 ; D P=10,80)$ e $80,6 \%(n=262)$, relataram que dirigem todos os dias. Do total de participantes, 31\% $(n=101)$ relataram ter tido infrações de trânsito no ano de 2014, além disso, $46,01 \%(n=150)$ já sofreram algum acidente de trânsito, no entanto, desses motoristas, apenas $14,72 \%(n=48)$ relataram terem sido responsabilizados e os demais relataram que foram vítimas dos acidentes. 


\section{Instrumentos}

Questionário de Identificação. O questionário de identificação foi construído para obtenção de informações como sexo, idade, estado civil, tempo de carteira de motorista, categoria da habilitação ( $\mathrm{A}, \mathrm{B}, \mathrm{AB}, \mathrm{C}, \mathrm{D}, \mathrm{E})$, frequência com que dirige (uma vez ou mais por dia; uma vez por semana; raramente dirige), quantas multas teve no ano de 2014 e envolvimento em acidentes de trânsito (danos materiais; com vítima).

Questionário de Comportamento do Motorista-QCM. O QCM foi desenvolvido por Reason et al. (1990) na Inglaterra e adaptado para o Brasil por Veiga et al. (2009). Primeiramente, foi feita a tradução por três profissionais bilíngues, além disso, foi realizada a análise semântica com 12 sujeitos com escolaridade de ensino médio e superior. A partir disso, alguns itens foram eliminados e outros reformulados pelas diferenças entre os sistemas viários dos dois países. A versão final do instrumento, com 67 itens e opções de resposta com cinco pontos variando de nunca a sempre, foi aplicada em 504 motoristas do Distrito Federal. Os resultados indicaram, por meio da análise fatorial exploratória, uma versão final de 39 itens, distribuídos em três fatores com 13 itens cada um, erros (ocorrem devido a falhas no processamento da informação, $\alpha=0,80$ ), lapsos (são ações não-intencionais, $\alpha=0,76$ ) e violações (existe a intenção deliberada de infringir uma norma, $\alpha=0,76$ ).

Escala de Lócus de Controle no Trânsito (T-LOC-BR). A escala com 16 itens foi inicialmente desenvolvida por Özkan e Lajunen (2005) e adaptada para o Brasil por Olandoski (2012). $\mathrm{Na}$ versão brasileira, aplicada a 172 motoristas do Paraná, foi incluído um item sobre o uso de bebidas alcoólicas, assim a versão com 17 itens distribuídos em uma escala com pontuações do tipo Likert com cinco pontos, sendo 1 ponto atribuído à resposta 'sem a menor possibilidade' até 5 pontos conferidos para à resposta 'alta possibilidade'. A análise fatorial exploratória indicou três fatores: (a) internalidade, no qual o sujeito é responsável por suas ações, com sete itens $(\alpha=0,85)$; (b) externalidade-outros, no qual a responsabilidade do acidente é atribuída a Deus, políticos, divindades e aos pais, com sete itens $(\alpha=0,63)$; (c) externalidade-acaso, no qual a responsabilidade do acidente é do destino, da sorte e azar, com três itens $(\alpha=0,40)$.

Inventário Multidimensional de Estilo de direção. O Multidimensional Driving Style Inventory (MSDI) foi desenvolvido por Taubman-Ben-Ari et al. (2004) e aplicado em 500 motoristas. Após a análise fatorial, o instrumento foi reduzido para 44 itens, distribuídos em oito escalas. Para adaptação no Brasil, o instrumento foi traduzido para o português e analisado por pesquisadores com domínio em inglês. Depois, o instrumento foi revertido novamente para o inglês por um especialista no idioma. A versão com as alterações necessárias foi aplicada em 250 motoristas, com pontuações no formato Likert de seis pontos, com itens variando de "nunca" (0) a "sempre" (6). Os resultados da análise fatorial também indicaram oito escalas e a confiabilidade avaliada por meio do alfa de Cronbach foi para o estilo estressado $(\alpha=0,77)$, agressivo $(\alpha=0,73)$, negligente $(\alpha=0,55)$, perigoso $(\alpha=0,55)$, senso-emocional $(\alpha=0,67)$, preventivo $(\alpha=0,64)$, relaxante $(\alpha=0,57)$ e desatento $(\alpha=$ $0,63)$. A confiabilidade também foi avaliada pelo teste-reteste em $10 \%$ da amostra $(n=25)$ seis meses depois da primeira aplicação, sendo estabelecida uma somatória de cada sujeito que respondeu ao questionário e por meio da correlação de Pearson foi verificado resultado moderado ( $r$ $=0,66, p<0,05)$. Vale ressaltar que se considera que os valores de $\alpha$ obtidos no estudo de adaptação do instrumento ao Brasil são considerados baixos, com base em Urbina (2007). Entretanto, optou-se por incluí-la, mesmo assim, por ser um instrumento bastante utilizado no cenário internacional, e por não haver outros que mensurem este construto que já tenham sido adaptados para a população brasileira.

\section{Procedimento de Coleta de Dados}

Com a aprovação do Comitê de Ética em Pesquisa com Seres Humanos, a autorização do DETRAN/PR e das proprietárias das clínicas, iniciou-se a coleta dos dados. Os candidatos à renovação que tiveram resultado de "apto" na avaliação de aptidão física e mental eram encaminhados, individualmente, a uma sala previa- 
mente preparada para a realização da pesquisa. Então, a pesquisadora se apresentava, informava que o resultado no exame médico havia sido "apto", bem como os motivos para o candidato ter sido encaminhado até a sala. Com isso, apresentava os objetivos da pesquisa e, principalmente, ressaltava que a participação era voluntária, que os dados seriam mantidos em sigilo, que os procedimentos do Departamento Estadual de Trânsito (DETRAN) e da pesquisa eram distintos e independentes e que a avaliação não era obrigatória, e caso não aceitassem participar não haveria nenhuma consequência no seu processo de renovação. Os condutores que aceitaram participar da pesquisa assinaram o Termo de Consentimento Livre e Esclarecido (TCLE) e a pesquisadora explicava a forma de realização de cada instrumento. A aplicação foi individual e o tempo aproximado de cada aplicação foi de 30 minutos.

Nas universidades, os dados foram coletados após a autorização dos Coordenadores dos cursos e dos professores em horário previamente agendado. Os alunos que estavam em aulas nesses dias eram convidados a participarem da pesquisa, após a explicação sobre os objetivos, o caráter voluntário e o sigilo das informações. Os estudantes que tinham a Carteira Nacional de Habilitação (CNH) e aceitaram participar da pesquisa, assinaram o Termo de Consentimento Livre e Esclarecido. A aplicação foi coletiva, com tempo aproximado de 30 minutos.

\section{Procedimento de Análise dos Dados}

Os dados foram tabulados e analisados com o software estatístico Statistical Package for Social Sciences (SPSS), versão 20.0 e submetidos aos seguintes procedimentos. Para verificar a relação entre os escores dos instrumentos foi usada a correlação de Pearson, controlando-se as variáveis: sexo, idade, tempo de habilitação e frequência com que dirige. A correlação de Pearson também foi utilizada para verificar a relação dos fatores do QCM, T-LOC-BR e MSDI com número de multas e acidentes de trânsito, idade, tempo de habilitação e frequência com que dirige. Para a comparação das variáveis sexo, escolaridade e estado civil com os fatores do QCM,
T-LOC-BR e MSDI, foram utilizados o teste $t$ de Student e, para a duas últimas variáveis, uma ANOVA. Nas análises, foi considerado o resultado significativo ao nível de $5 \%(p<0,05)$.

\section{Resultados}

O objetivo inicial deste estudo foi verificar as relações existentes entre comportamento do motorista, lócus de controle e estilos de dirigir, controlando as variáveis sexo, idade, tempo de habilitação e frequência com que dirige. Na Tabela 1 , são apresentadas as correlações entre os fatores do Questionário de Comportamento do Condutor (QCM), da Escala de Lócus de Controle no Trânsito (T-LOC-BR) e do Inventário Multidimensional do Estilo de dirigir (MSDI).

Ao observar a Tabela 1, é possível verificar correlações estatisticamente significativas, de magnitude moderada, entre os fatores do QCM, erros com lapsos e violações, bem como entre os fatores lapsos e violações. Ademais, os fatores erros e lapsos apresentaram correlações significativas, de magnitude fraca, com os fatores do T-LOC-BR, internalidade, externalidade-outros e externalidade-acaso, enquanto o fator violações associado aos fatores internalidade e externalidade-acaso. Os resultados também indicaram que o fator internalidade apresentou correlações significativas e positivas, de magnitude fraca a moderada, com os fatores externalidade-acaso e externalidade-outros.

No que diz respeito aos fatores do QCM e os estilos de direção avaliados pelo MSDI, os resultados mostraram correlações estatisticamente positivas e significativas, de magnitude fraca, entre os fatores erros, lapsos e violações com os estilos, agressivo, negligente, perigoso e desatento, bem como dos fatores lapsos e violações com o estilo senso-emocional. Em acréscimo, como esperado, os três fatores do QCM apresentaram correlações significativas e negativas com o estilo preventivo.

Foi possível verificar correlações significativas e positivas, de magnitude alta, entre os fatores do T-LOC-BR, internalidade, externalidade-outros e externalidade ao acaso com o fator agressivo do MSDI. Os três fatores do lócus 


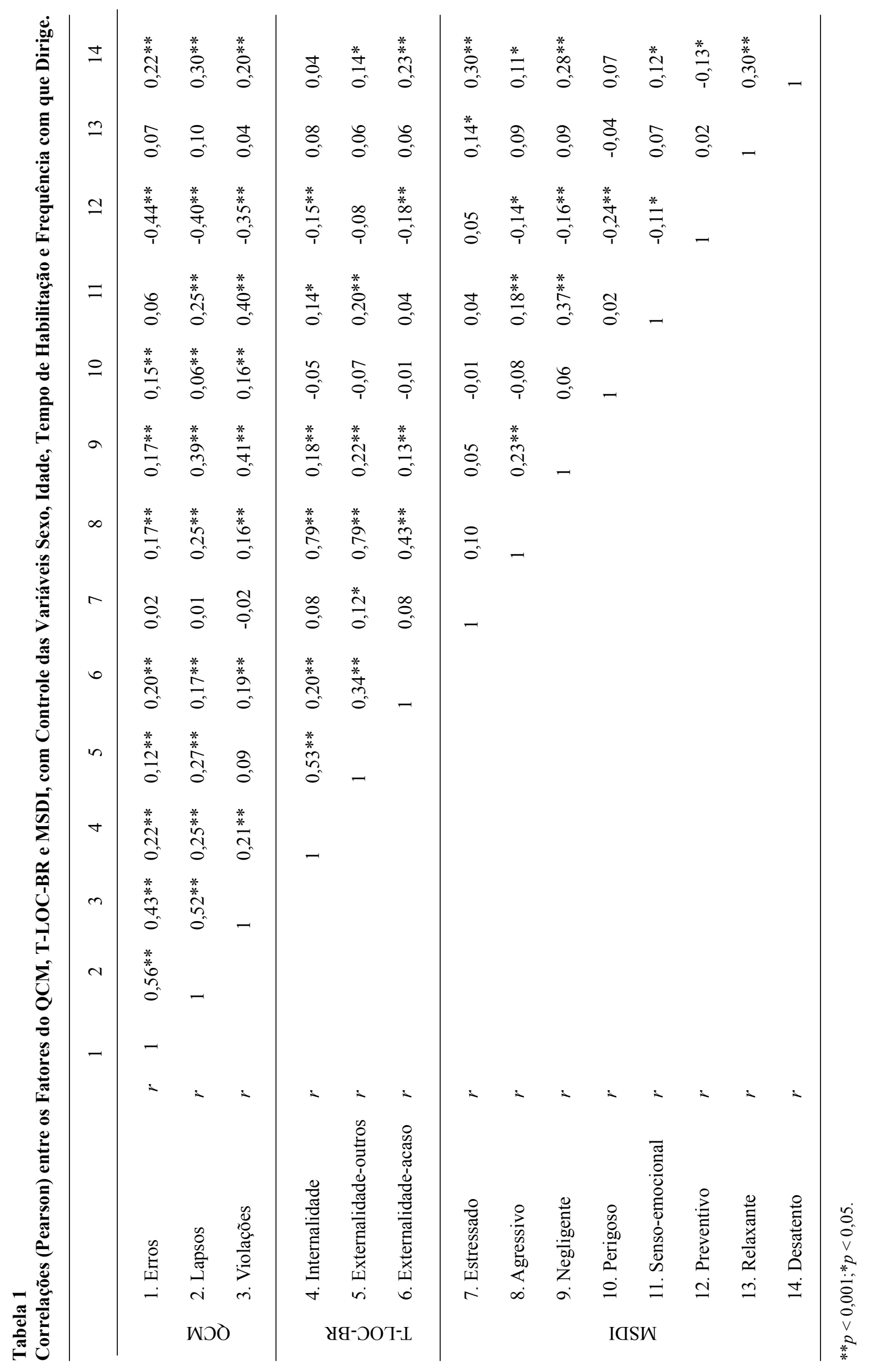


de controle apresentaram correlações positivas, de magnitude fraca, com o estilo de direção negligente. Por sua vez, os fatores do T-LOC-BR externalidade-outros e externalidade-acaso apresentaram correlações positivas com o estilo de direção senso-emocional. Por outro lado, os fatores internalidade e a externalidade-acaso do lócus de controle apresentaram correlações significativas e negativas com o estilo de direção preventivo.

$\mathrm{Na}$ verificação da relação entre os fatores do MSDI, foram encontradas correlações estatisticamente significativas e positivas, de magnitude fraca, entre os estilos agressivo e negligente, e esses dois apareceram associados positivamente ao estilo senso-emocional. Observa-se também que os estilos agressivo, negligente, perigoso e senso-emocional associados negativamente ao estilo preventivo. Contrariamente, o estilo estressado apresentou correlação positiva com o estilo relaxante. Igualmente, o estilo desatento associado aos estilos estressado, relaxante, agressivo, negligente e senso-emocional.

O segundo objetivo deste estudo consistiu em analisar a relação entre os fatores do QCM, do T-LOC-BR e do MSDI e as variáveis de autorrelato sobre infrações e envolvimento em acidentes de trânsito. Os resultados mostraram correlações positivas de magnitude fraca, entre o fator violações avaliadas pelo QCM com infrações $(r=0,14 ; p<0,001)$ e acidente de trânsito $(r=0,12 ; p=0,03)$. Os estilos negligente $(r=$ $0,19 ; p<0,001)$ e desatento $(r=0,17 ; p=0,002)$ apareceram correlacionados com o número de multas. Os acidentes de trânsito mostraram-se associados aos estilos de direção, estressado $(r$ $=0,11 ; p<0,001)$, ao negligente $(r=0,28 ; p$ $<0,001)$ e ao senso-emocional $(r=0,17 ; p=$ $0,002)$.

A correlação de Pearson também foi utilizada para a análise da relação entre as variáveis idade, tempo de habilitação e frequência com que dirige com os fatores avaliados pelo QCM, T-LOC-BR e MSDI. Também foram incluídas as variáveis número de multas do último ano e o envolvimento em acidentes. No entanto, os resultados indicaram apenas que a idade $(r=0,15$; $p<0,001)$ e o tempo de habilitação $(r=0,22 ; p$
$<0,001)$ estavam correlacionados com envolvimento em acidentes de trânsito, e a frequência de dirigir associada com o número de multas $(r$ $=0,14 ; p<0,001$ ).

Na comparação de médias nos fatores dos três instrumentos foram analisadas variáveis como sexo, escolaridade e estado civil. Os resultados indicaram diferenças estatisticamente significativas com maiores médias para as mulheres no fator lapsos $[t(240)=-3,27 ; p<0,01]$ do QCM, na externalidade-outros $[t(240)=$ $-2,28 ; p=0,02]$ do T-LOC-BR e no estilo agressivo $[t(240)=-2,40 ; p=0,02]$, do MSDI. Por sua vez, os homens apresentaram escores mais altos no estilo estressado $[t(240)=1,93 ; p=0,05]$, senso-emocional $[t(240)=2,49 ; p=0,01]$, e relaxante $[t(240)=3,51 ; p<0,01]$. No que diz respeito à escolaridade, os resultados indicaram diferenças significativas, mostrando que quanto maior o nível de instrução, maiores as médias no fator Lapsos do QCM $[F(3,322)=6,989 ; p=$ $0,01]$ e no estilo negligente do MSDI $[F(3,322)$ $=11,610 ; p<0,01]$. No que se refere ao estado civil, identificou-se que os solteiros apresentaram média maior que os casados/união estável no fator violações, $t(217)=3,20 ; p=0,04$, do QCM.

\section{Discussão}

Os objetivos deste estudo foram analisar a relação entre os comportamentos do condutor, lócus de controle no trânsito e estilos de direção, além de verificar as relações dos fatores dos instrumentos entre si e explorar variáveis como número de infrações, acidentes de trânsito e outras variáveis sociodemográficas. Muitos estudos estrangeiros têm mostrado que esses são construtos e variáveis importantes para a compreensão de comportamentos de risco dos motoristas no trânsito. No entanto, no Brasil, foram encontrados poucos estudos que tenham abordado os aspectos de interesse do presente trabalho, não tendo sido encontrado nenhuma pesquisa publicada que tenha focalizado os três construtos conjuntamente.

A análise que explorou a relação entre os fatores dos instrumentos indicou correlações 
estatisticamente significativas e positivas entre os escores de erros, lapsos e violações do Questionário de Comportamentos do Condutor (QCM). Com base nas definições dos fatores estabelecidos por Veiga et al. (2009), a associação entre erros e lapsos é esperada, já que uma falha no processamento de informação (erro) pode ocasionar uma ação não-intencional (lapsos). Autores como Özkan et al., (2006) e Steg e Brussel (2009) também salientam que tanto os erros como os lapsos são resultados de problemas no processamento das informações. Este mesmo raciocínio pode ser usado para explicar a relação encontrada entre lapsos e erros com violações, apesar de as violações serem, em geral, intencionais. A esse respeito, Cordazzo et al. (2014) alertam que os erros na direção ocorridos devido a falhas de atenção, inexperiência ou situações momentâneas, podem ocasionar violações de regras.

Em continuidade à exploração da relação entre os fatores dos instrumentos, foram identificadas, também, correlações positivas e significativas entre os fatores do T-LOC-BR, mostrando que os fatores de externalidade, se relacionaram entre si e ambos com o fator internalidade. $\mathrm{Pa}$ rece compreensível este resultado, pois embora existam dois pólos - interno e externo -, eles não são opostos, uma vez que o motorista pode atribuir as causas de um acidente tanto a fatores internos, por exemplo, relativo às suas habilidades, como também a fatores externos como o destino ou a falta de manutenção nas estradas.

$\mathrm{Na}$ análise da associação entre os fatores do T-LOC-BR e do QCM, observou-se que os fatores internalidade e externalidade-acaso associaram-se ao fator violação. Este resultado é divergente do obtido por Olandoski (2012) ao correlacionar o T-LOC-BR com uma adaptação do Driver Behaviour Questionnaire (DBQ), diferente da utilizada no presente estudo. Nos resultados relatados pelo autor, foram encontradas diversas correlações positivas e significativas, de magnitude fraca, entre o fator internalidade com erros e lapsos do DBQ, o fator externalidade-acaso com lapsos, e o fator externalidade-outros com fator violações do DBQ. Pode-se atribuir os resultados diferentes detectados entre os dois es- tudos às diferenças do instrumento. A adaptação brasileira do QCM apresenta alterações em relação ao número de itens e fatores quando comparado ao DBQ, bem como a alocação dos itens em seus respectivos fatores.

Para os fatores avaliados pelo QCM e o MSDI, foram encontradas correlações estatisticamente positivas e significativas entre os erros, lapsos e violações com os estilos agressivo, negligente, perigoso e desatento. Com base no significado de cada um dos fatores do MSDI (Silva, 2004), é possível inferir que os motoristas com maior possibilidade de relatarem erros, lapsos e violações no trânsito, são os motoristas com tendência à agressividade. $\mathrm{O}$ mesmo ocorre com aqueles identificados como negligentes, com os perigosos que infringem as leis e gostam de correr riscos, podendo acontecer, também, com os motoristas desatentos. Do mesmo modo, o motorista com predominância do estilo senso-emocional tende a apresentar mais erros e lapsos, visto que gosta da emoção de dirigir perigosamente e procura maneiras de atravessar o trânsito o mais rápido possível.

Além do mais, como esperado teoricamente, o estilo preventivo referente àqueles motoristas, que dirigem cautelosamente e com cuidado, apareceu associado de maneira significativa e negativa com os três fatores do QCM, erros, lapsos e violações. $\mathrm{O}$ fator preventivo também apresentou correlações negativas com os fatores internalidade e externalidade-acaso do T-LOC-BR, ou seja, esses motoristas tendem a não atribuir as causas dos acidentes de trânsito às suas próprias ações e nem ao acaso, como o destino. Há pesquisadores que defendem a ideia de que a internalidade esteja ligada a comportamentos de condução segura (Hoyt, 1973; Huang \& Ford, 2012; Lajunen \& Summala, 1995), apesar de não haver consenso na literatura sobre qual a forma de atribuição mais adequada para evitar os acidentes de trânsito, se a fatores internos ou externos.

Explorando ainda mais os fatores do $\mathrm{T}$ -LOC-BR e os outros estilos de direção, foram encontradas correlações positivas entre a internalidade, externalidade-acaso, externalidade-outros e os estilos agressivo e negligente, bem 
como entre os últimos dois fatores do T-LOC-BR e o estilo desatento. Observou-se, também, a associação da internalidade e externalidade-outros com o estilo senso-emocional, e dos dois fatores de externalidade do T-LOC-BR com o estilo estressado. Com base nos resultados, constatou-se que os motoristas com estilos de direção agressivo, negligente, desatento, senso-emocional e estressado, tendem a atribuir as causas de acidentes de trânsito a fatores externos a si. Pode-se observar uma semelhança com o estudo de Holland et al. (2010), no qual o lócus de controle externo esteve associado aos estilos de condução senso-emocional, estressado e perigoso.

As discussões na literatura sobre o lócus de controle no trânsito sugerem que os motoristas, que diante dos acidentes automobilísticos responsabilizam os fatores externos, podem ser mais resistentes para mudar os seus comportamentos (Huang \& Ford, 2012). Da mesma forma, os motoristas podem apresentar maior dificuldades para se precaverem de desfechos desfavoráveis na direção (Özkan et al., 2011), além de apresentarem maiores chances de se envolverem em acidentes fatais (Montag \& Comrey, 1987). No entanto, vale a ressalva de que os motoristas com estilos agresssivo, negligente e senso-emocional da amostra estudada na presente pesquisa, também atribuem os acidentes a fatores internos, ou seja, admitem que os seus comportamentos também possam ocasionar acidentes de trânsito. Em razão disso, acredita-se que as intervenções educativas com esses motoristas são necessárias e podem ser efetivas.

Considerando a proposição de TaubmanBen-Ari et al. (2004) de que os estilos de direção são interrelacionados, a correlação entre os estilos, avaliados pelo MSDI, foi aqui analisada. Os resultados mostraram correlações estatisticamente significativas e positivas entre o estilo negligente e o agressivo e entre esses dois estilos, com o senso-emocional. Com base nas descrições sobre os fatores (Silva, 2004), entende-se que essas relações são esperadas, pois uma das características do estilo negligente é a falta de planejamento da sua rota antes de sair de casa, o que pode levar, na situação de pressa, à impaciência com um trânsito pesado e, consequentemente, a expressões que podem ser consideradas agressivas. Por sua vez, motoristas que apresentam maior busca por sensação e agressividade tendem a expressar maior raiva e direção arriscada quando estão dirigindo (Poó \& Ledesma, 2013; Poó et al., 2013). Essas dificuldades na regulação emocional também estão associadas aos estilos de condução ansioso, irritado, dissociativo e arriscado (Trógolo et al., 2013). Verifica-se assim, que os comportamentos no trânsito são resultados de uma associação entre emoções, características de personalidade e estilos de direção, e que quanto menos adequados podem levar a situações de risco com grande possibilidade de envolvimento em acidentes de trânsito.

Em contraste com essas situações e considerando a descrição do estilo preventivo (Silva, 2004), os resultados demonstraram, tal como esperado, que se ele se associou negativamente com os estilos agressivo, negligente, perigoso, senso-emocional e desatento. No estudo de Silva (2004), o estilo preventivo apareceu associado negativamente apenas ao estilo desatento. No estudo de Poó et al. (2013), a condução cuidadosa apareceu correlacionada negativamente com a busca por sensação e agressividade. Os autores detectaram, ainda, associação entre os estilos estressado e relaxante, visto ser possível que aqueles motoristas, que se sentem desconfortáveis e nervosos enquanto dirigem, procuram maneiras de aliviar a tensão, ouvindo música, por exemplo.

Correlacionar as variáveis sociodemográficas e os fatores do QCM, do T-LOC- BR e do MSDI, bem como com número de multas e de acidentes de trânsito também foi objetivo desta pesquisa. Estabeleceu-se este objetivo pelo fato de a literatura apontar para diversas dessas variáveis como determinantes do ato de dirigir, dentre elas, o sexo, idade, escolaridade, número de multas e acidentes, e até a cultura de um país (Holland et al., 2010; Mesken et al., 2002; Olandoski, 2012; Pasa, 2013; Soares, 2007). Deste modo, verificaram-se correlações positivas entre o fator violações avaliadas pelo QCM e o número de infrações e acidente de trânsito. Apesar das magnitudes dessas correlações serem baixas, al- 
guns estudos têm também identificado resultado semelhante, além de relatarem o fator violações do QCM como preditor para o envolvimento em acidentes (DeLucia et al., 2003; Olandoski, 2012; Özkan \& Lajunen, 2005; Winter \& Dodou, 2010).

Diferentemente de Olandoski (2012) e Özkan e Lajunen (2005), que encontraram associações entre os fatores internos e externos do lócus de controle associados a número de multas e acidentes de trânsito, estas não foram encontradas no presente estudo. Em relação aos estilos de direção, encontrou-se que tanto o estilo negligente quanto o desatento apareceram correlacionados ao número de multas e, por outro lado, os estilos negligente, estressado e o senso-emocional mostraram-se correlacionados ao número de acidentes de trânsito. Como é possível analisar, o estilo negligente correlacionou-se positivamente com infrações e acidentes, o que é congruente com os dados de outros estudos (Miller \& Taubman-Ben-Ari, 2010; Taubman-Ben-Ari et al., 2005).

$\mathrm{Na}$ análise das variáveis idade e tempo de habilitação, os resultados indicaram apenas associação positiva com acidentes de trânsito, enquanto a frequência de dirigir apareceu associada ao número de multas. Esses resultados são diferentes dos de outros estudos, tais como o de Mesken et al. (2002) e Winter e Dodou (2010), nos quais a idade apareceu associada positivamente com erros avaliado pelo QCM, bem como negativamente associada a violações. Na pesquisa de Olandoski (2012), o tempo de habilitação apareceu associado à atribuição dos acidentes de trânsito a fatores internos; e motoristas com mais de 23 anos de idade apresentaram médias maiores no fator externalidade-outros. Na mesma direção, Silva (2004) encontrou em seu estudo que a idade apareceu negativamente correlacionada com os estilos perigoso, senso-emocional e desatento e positivamente associada ao estilo preventivo.

Nas comparações para a variável sexo, foram encontradas diferenças significativas com maiores médias para as mulheres apenas no fator lapsos do QCM, em externalidade-outros do T-LOC-BR e no estilo agressivo do MSDI. Ou- tros estudos têm verificado resultados diversos, como o de Mesken et al. (2002) que encontraram maiores médias no fator erros para as mulheres e o de Olandoski (2012) que identificou maiores médias nos fatores de externalidade, no que se refere a outros motoristas e também ao acaso. Por sua vez, no estudo de Holland et al. (2010), as mulheres apresentaram médias mais altas nos estilos de condução relaxante, preventivo e desatento. Para esse último estilo de direção, Silva (2004) encontrou resultado similar.

Ainda em relação à comparação entre os sexos, identificou-se diferenças significativas com maiores médias para os homens apenas no MSDI, especificamente no estilo estressado, senso-emocional e preventivo, diferentemente dos resultados encontrados por Silva (2004). Os resultados desta pesquisa se assemelham aos apresentados por Holland et al. (2010), com maiores médias para os homens no estilo estressado, perigoso e negligente. Outros estudos têm detectado diferenças significativas no QCM, com maiores médias para os homens em violações (Correia \& Horta, 2014) e em erros (Soares, 2007).

Quanto à escolaridade, os resultados encontrados no presente estudo indicaram que quanto maior o nível de instrução, maiores são as médias no fator Lapsos do QCM e no estilo negligente do MSDI, tais dados se diferenciam dos achados de Pasa (2013), no qual os anos de estudo apareceram como um fator de segurança para comportamentos de risco. Quanto à variável estado civil, os resultados indicaram que os solteiros apresentaram média maior que os casados/união estável no fator violações do QCM. No entanto, no estudo de Soares (2007) não foram encontradas diferenças significativas entre os fatores do QCM para o estado civil. Com relação a ambas as variáveis, caberá a realização de novos estudos, em busca do esclarecimento dessas questões.

Esta investigação teve como principal finalidade analisar de forma exploratória as relações existentes entre os construtos e as variáveis sociodemográficas. Muitos dos achados não puderam ser discutidos devido à falta de estudos que tenham investigado as mesmas variáveis principalmente, no contexto nacional. Adicionalmen- 
te, muitos resultados encontrados diferem dos apresentados nos poucos estudos publicados. Em parte, este fato é compreensível, uma vez que o comportamento do motorista é um fenômeno bastante complexo, sendo influenciado por diversas variáveis intervenientes, dentre elas aspectos individuais e socioculturais.

Apesar das contribuições aqui trazidas, este estudo apresenta limitações, tal como o fato de os resultados não poderem ser generalizados aos motoristas brasileiros, uma vez que a amostra incluiu apenas motoristas de dois estados. Além disso, devem-se ponderar os resultados, considerando aspectos como a desejabilidade social, característica de instrumentos de autorrelato, como também o fato de grande parte da coleta ter ocorrido em clínicas credenciadas ao DETRAN. Vale lembrar, por fim, que embora os instrumentos tenham evidências de validade para o Brasil, as estimativas de precisão obtidas nos estudos de adaptação estão abaixo do nível adequado indicado por Urbina (2007) e se aplica especialmente ao T-LOC-BR para os fatores externalidade-outros $(\alpha=0,63)$ e externalidade-acaso $(\alpha=0,40)$ e ao MSDI para os estilos negligente, perigoso, senso-emocional, preventivo, relaxante e desatento com alfa próximo ou abaixo de 0,60 .

Deste modo, sugere-se que novos estudos sejam realizados com esses instrumentos a fim de aprimorar as suas qualidades psicométricas, por meio das adaptações necessárias, ou com a construção de outras medidas que avaliem esses construtos na realidade brasileira. É importante que seja também considerado o fato de que os números de veículos e de motoristas têm aumentado significativamente no Brasil, um fator que exigirá novas e constantes pesquisas na área.

A agenda de pesquisa sobre o tema deve também incluir novas investigações, por exemplo, apurando o número de pessoas consideradas aptas no processo de concessão da Carteira Nacional de Habilitação e o número de acidentes em certos estados brasileiros, a fim de fomentar discussões sobre a necessidade de aprimoramentos nos procedimentos da avaliação psicológica pericial e sobre a influência dos aspectos socioculturais no comportamento e estilo de dirigir dos motoristas. Essas e outras informações sobre os comportamentos dos condutores são fundamentais para a elaboração de programas de intervenção.

\section{Referências}

Cordazzo, S. T. D., Scialfa, C., Bubric, K., \& Ross, R. J. (2014). The Driver Behaviour Questionnaire: A North American analysis. Journal of Safety Research, 50, 99-107. doi:10.1016/j. jsr.2014.05.002

Correia, J. P., \& Horta, M. P. C. (2014). Personalidade e comportamentos de risco de motoristas: diferenças entre sexos. Psicologia: Teoria $e$ Prática, 16(1), 79-90.

DeLucia, P. R., Bleckley, M. K., Meyer, L. E., \& Bush, J. M. (2003). Judgments about collision in younger and older drivers. Transportation Research Part F, 6, 63-80.

Freeman, J., Wishart, D., Davey, J., Rowland, B., \& Williams, R. (2009). Utilising the Driver Behaviour Questionnaire in an Australian organizational fleet setting: Can it identify risky drivers? Journal of the Australasian College of Road Safety, 20, 38-45.

Hoffmann, M. H. (2005). Comportamento do condutor e fenômenos psicológicos. Psicologia: Pesquisa \& Trânsito, 1(1), 17-24.

Holland, C., Geraghty, J., \& Shah, K. (2010). Differential moderating effect of locus of control on effect of driving experience in young male and female drivers. Personality and Individual Difference, 48(7), 821-826. doi:http://dx.doi. org/10.1016/j.paid.2010.02.003

Hoyt, M. F. (1973). Internal-external control and beliefs about automobile travel. Journal of Research in Personality, 7, 288-293.

Huang, J. L., \& Ford, J. K. (2012). Driving locus of control and driving behaviors: Inducing change through driver training. Transportation Research Part F: Traffic Psychology and Behaviour, 15, 358-368.

Lajunen, T., \& Summala, H. (1995). Driving experience, personality, and skill and safety-motive dimensions in drivers' self-assessments. Personality and Individual Differences, 19, 307-318.

Lajunen, T., \& Summala, H. (2003). Can we trust self-reports of driving? Effects of impression 
management on driver behaviour questionnaire responses. Transportation Research Part F, 6 , 97-107.

Mesken, J., Lajunen, T., \& Summala, H. (2002). Interpessonal violations, speeding violations and their relation to accident involvement in Filand. Ergonomics, 45(7), 469-483.

Miller, G., \& Taubman-Ben-Ari, O. (2010). Driving styles among young novice drivers - The contribution of parental driving styles and personal characteristics. Accident Analysis and Prevention 42, 558-570. doi:10.1016/j.aap.2009.09.024

Montag, I., \& Comrey, A. L. (1987). Internality and externality as correlates of involvement in fatal driving accidents. Journal of Applied Psychology, 72, 339-343. doi:http://dx.doi. org/10.1037/0021-9010.72.3.339

Monteiro, C. A. S., \& Günter, H. (2006). Agressividade, raiva e comportamento de motorista. Psicologia: Pesquisa \& Trânsito, 2(2), 9-17.

Olandoski, G. P. (2012). Comportamento de condução e lócus de controle (Dissertação de mestrado, Universidade Federal do Paraná, Curitiba, PR, Brasil).

Özkan, T., \& Lajunen, T. (2005). Multidimensional traffic locus of control scale (T-LOC). Factor structure and relationship to risky driving. Personality and Individual Differences, 38, 533545. doi:10.1016/j.paid.2004.05.007

Özkan, T., Lajunen, T., \& Summala, H. (2006). Driver behaviour questionnaire: A followup study. Accident Analysis and Prevention, 38, 386-395.

Özkan, T., Lajunen, T., Doğruyol, B., Zümrüt, Y., \& Çoymak, A. (2011). Motorcycle accidents, rider behaviour, and psychological models. $A c$ cident Analysis and Prevention, 39, 491-499. doi:10.1016/j.aap.2011.03.009

Pasa, G. G. (2013). Impulsividade, busca de sensações e comportamentos de risco no trânsito: $U m$ estudo comparativo entre condutores infratores e não infratores (Dissertação de mestrado, Universidade Federal do Rio Grande do Sul., Porto Alegre, RS, Brasil).

Poó, F., \& Ledesma, R. D. (2013). A study on the relationship between personality and driving styles. Traffic Injury Prevention, 14, 346-352. doi:10.1080/15389588.2012.717729

Poó, F., Taubman-Ben-Ari, O., Ledesma, R., \& DíazLázaro, C. (2013). Reliability and validity of a
Spanish-language version of the multidimensional driving style inventory. Transportation Research Part F, 17, 75-87.

Reason, J., Manstead, A., Stradling, S., Baxter, J., \& Campbell, K. (1990). Errors and violations on the roads: A real distinction. Ergonomics, 33, 1315-1332.

Rimmö, P. A., \& Hakamies-Blomqvist, L. (2002). Older drivers aberrant driving behaviour, impaired activity, and health as reasons for selfimposed driving limitations. Transportation Research Part F, 5, 47-62.

Rozestraten, R. J. A. (1988). Psicologia do Trânsito: Conceitos e processos básicos. São Paulo, SP: EPU.

Steg, L., \& Brussel, A. (2009). Accidents, aberrant behaviours, and speeding of young moped riders. Transportation Research Part F, 12(6), 503-511.

Stephens, A. N., \& Groeger, J. A. (2009). Situational specificity of trait influences on drivers' evaluations and driving behaviour. Transportation Research Part F: Traffic Psychology and Behaviour, 12(1), 29-39.

Silva, L. C. P. (2004). Análise psicométrica do inventário multdimensional do estilo de dirigir (MSDI - Multidimensional Driving Style Inventory) (Dissertação de mestrado, Universidade de São Paulo, SP, Brasil).

Soares, R. C., Jr. (2007). Comportamento de risco no trânsito de motoristas em Campo Grande-MS (Dissertação de mestrado, Universidade Católica Dom Bosco, Campo Grande, MS, Brasil).

Taubman-Ben-Ari, O., Mikulincer, M., \& Gillath, M. (2004). The muldimensional driving style inventory-scale construct and validation. Accident Analysis \& Prevention, 952, 1-10. doi:https:// doi.org/10.1016/S0001-4575(03)00010-1

Taubman-Ben-Ari, O., Mikulincer, M., \& Gillath, O. (2005). From parents to children - Similarity in parents and offspring driving styles. Transportation Research Part F: Traffic Psychology and Behaviour, 8(1), 19-29.

Tawamoto, J. M., \& Capitão, C. G. (2010). Evidências de validade do teste de Pfister: Agressividade e irritabilidade em motoristas. Estudos Interdisciplinares em Psicologia, 1(1), 40-65. doi:http:// dx.doi.org/10.5433/2236-6407.2010v1n1p40 
no Trânsito.

Trógolo, M. A., Melchior, F., \& Medrano, L. A. (2013). The role of difficulties in emotion regulation on driving behavior. Journal of Behavior, Health \& Social, 6(1), 107-117. doi:10.5460/ jbhsi.v6.1.47607

Urbina, S. (2007). Fundamentos da testagem psicológica. Porto Alegre, RS: Artmed.

Veiga, H. M. S., Pasquali, L., \& Silva, I. (2009). Questionário do comportamento do motorista QCM. Adaptação e validação para a realidade brasileira. Avaliação Psicológica, 8(2), 187-196.

Wahlberg, A., Dorn, L., \& Kline, T. (2011). The Manchester driver behaviour questionnaire as a predictor of road traffic accidents. Theoretical Issues in Ergonomics Science, 12, 66-86. doi:http:// dx.doi.org/10.1080/14639220903023376

Wahlberg, A., Dorn, L., Winter, J. C. F., Dodou, D., \& Freeman, J. E. (2012). Commentaries and responses to "The Driver Behaviour Questionnaire as a Predictor of Accidents: A Meta-analysis". Journal of Safety Research, 43(1), 83-99.
Warner, H. W., Özkan, T., \& Lajunen, T. (2010). Can the traffic locus of control (T-LOC) scale be successfully used to predict Swedish drivers' speeding behaviour? Accident Analysis and Prevention, 42, 1113-1117.

Winter, J. C. F., \& Dodou, D. (2010). The Driver Behaviour Questionnaire as a predictor of accidents: A meta-analysis. Journal of Safety Research, 41, 463-470. doi:10.1016/j.jsr.2010.10.007
Recebido: 30/07/2015

$1^{a}$ revisão: 02/05/2016

$2^{a}$ revisão: $20 / 07 / 2016$ Aceite final: 15/08/2016 